\section{Proton pump inhibitor use associated with changes in gut microbiota composition}

We read with great interest the recent publications in Gut by Imhann et al and Jackson et al, which assessed the impact of proton pump inhibitor (PPI) use on gut microbiota diversity and composition in humans. ${ }^{12}$ PPIs are one of the most commonly used drug classes worldwide. Once initiated, they are often used chronically without clear therapeutic intent. ${ }^{3}$ PPIs alter GI $\mathrm{pH}^{4}$ and delay gastric emptying rate, ${ }^{5}$ which could directly affect gut microbiota and survival of enteric pathogens. Using three independent cohorts (211 PPI users and 1604 non-users), Imhann et $a l^{1}$ reported a significant decrease in alpha diversity and changes in 20\% of bacterial taxa in PPI users compared with non-users.
Among 1827 healthy twins, Jackson et $a l^{2}$ also found a significant decrease in alpha diversity and alteration of bacterial composition in PPI users. Notably, both studies found a higher abundance of oral commensals, including Streptococcaceae, among PPI users. These studies controlled for some potential confounders in their analyses; however, intersubject variability could have influenced their results.

We assessed the impact of PPI use on the gut microbiota composition in a prospective study of healthy older adults (age $\geq 60$ years) from San Antonio, Texas, USA. Participants provided a stool sample at baseline, completed a 14-day course of omeprazole $20 \mathrm{mg}$ daily and then provided a follow-up stool sample. Stool 16 s rRNA V4 sequences were amplified and sequenced on the Illumina MiSeq platform. Sequences were clustered into operational taxonomic units (OTUs) and classified via mothur's Bayesian classifier referenced against the Greengenes database. Abundance-weighted sample differences were calculated using the Bray-Curtis dissimilarity. PERMANOVA was used to assess the impact of PPI use on beta diversity.

A total of 24 subjects completed the study (mean age 71.4 years and $62.5 \%$ women). Mean $( \pm \mathrm{SD})$ OTU richness was similar between pre-PPI $(485 \pm 84.3)$ and post-PPI $(496 \pm 88.7)$ samples $(p=0.32)$. Additionally, Shannon diversity was not statistically different between pre-PPI $(3.86 \pm 0.27)$ and post-PPI $(3.92 \pm 0.31)$

Table 1 Comparison of taxa relative abundance in pre-PPI and post-PPI samples

\begin{tabular}{lccl}
\hline Bacteria* & Pre-PPI mean (SD) & Post-PPI mean (SD) & p Value \\
\hline Phylum & & & \\
\hline Firmicutes & $70.70(10.40)$ & $69.00(10.40)$ & 0.5531 \\
\hline Bacteroidetes & $20.60(12.30)$ & $24.00(10.70)$ & 0.0914 \\
\hline Actinobacteria & $4.25(4.76)$ & $2.35(2.44)$ & 0.0059 \\
\hline Proteobacteria & $2.51(2.96)$ & $3.01(2.55)$ & 0.2296 \\
\hline Verrucomicrobia & $1.14(4.22)$ & $1.10(2.80)$ & 0.7726 \\
Euryarchaeota & $0.65(1.75)$ & $0.20(0.54)$ & 0.3242 \\
\hline Tenericutes & $0.13(0.44)$ & $0.22(0.71)$ & 0.2708 \\
Cyanobacteria & $0.02(0.08)$ & $0.04(0.11)$ & 0.4591 \\
\hline Family & & & 0.0059 \\
Lachnospiraceae & $33.40(20.50)$ & $28.60(7.70)$ & 0.6373 \\
Ruminococcaceae & $20.50(9.35)$ & $21.30(7.98)$ & 0.1961 \\
\hline Bacteroidaceae & $13.40(10.70)$ & $14.90(9.33)$ & 0.0009 \\
\hline Streptococcaceae & $1.49(1.91)$ & $5.93(5.30)$ & 0.6814 \\
\hline Prevotellaceae & $3.21(8.23)$ & $4.09(9.87)$ & 0.0132 \\
\hline Erysipelotrichaceae & $4.09(3.30)$ & $2.74(3.69)$ & 0.0275 \\
Bifidobacteriaceae & $2.83(4.39)$ & $1.39(2.09)$ & 0.0914 \\
\hline Rikenellaceae & $1.61(1.23)$ & $2.14(1.90)$ & \\
\hline Boldvalusindica) & & \\
\hline
\end{tabular}

Bold values indicate statistical significance at $p<0.05$.

*Table includes only the eight most commonly identified phyla and families.

PPI, proton pump inhibitor. 
samples $(p=0.28)$. Pre-PPI samples had significantly higher relative abundance of the phylum Actinobacteria and the families Lachnospiraceae, Erysipelotrichaceae and Bifidobacteriaceae (table 1). Post-PPI samples had significantly higher abundance of Streptococcaceae. Beta diversity was significantly associated with PPI use $(\mathrm{p}<0.0001)$.

In line with our findings, Jackson et $a l^{2}$ found higher Streptococcaceae and lower Lachnospiraceae and Erysipelotrichaceae abundance in PPI users compared with non-users. Imhann et $a l^{1}$ also noted that PPI users had enrichment for Streptococcaceae, but a lower abundance of Bifidobacteriaceae. Of note, decreased Bifidobacterium is associated with Clostridium difficile infection (CDI), ${ }^{6}$ whereas supplementation with Bifidobacterium is associated with reduced risk of developing CDI in humans. ${ }^{7}$ Similarly, the abundance of Streptococcaceae is significantly increased in CDI, while Lachnospiraceae are reduced compared with healthy controls. ${ }^{8}$ While studies have been somewhat inconsistent, a 2012 meta-analysis of 42 studies found that PPI use was associated with an increased risk for initial and recurrent CDI. ${ }^{9}$ This led the US Food and Drug Administration to issue a drug safety warning in 2012 regarding this association. Changes in gut microbiota composition could help explain this association. Our findings, in addition to those of Imhann et al and Jackson et al, highlight the potential for PPIs to affect health through alteration of the gut microbiota and the need to limit inappropriate and unnecessary use of PPIs.

\section{Kelly R Reveles, ${ }^{1,2}$ Caitlin N Ryan, ${ }^{3}$ Luisa Chan, ${ }^{3}$ Reese A Cosimi, ${ }^{1,4}$ Wanda L Haynes ${ }^{5}$}

${ }^{1}$ College of Pharmacy, The University of Texas at Austin, San Antonio, Texas, USA
${ }^{2}$ Pharmacotherapy Education and Research Center, UT Health San Antonio, San Antonio, Texas, USA

${ }^{3}$ Second Genome, Inc., San Francisco, California, USA

${ }^{4}$ South Texas Veterans Healthcare System, San Antonio, Texas, USA

${ }^{5}$ Institute for Integration of Medicine and Science, UT Health San Antonio, San Antonio, Texas, USA

Correspondence to Dr Kelly R Reveles, UT Health San Antonio, Pharmacotherapy Education and Research Center, San Antonio, TX 78229-3900, USA; kdaniels46@utexas.edu

Acknowledgements The authors would like to thank the staff at the First Outpatient Research Unit, UT Health San Antonio and at Second Genome, Inc. for their assistance with study procedures. KR would also like to acknowledge the San Antonio Claude D Pepper Older Americans Independence Center's leaders for their invaluable project mentorship: Nicolas Musi, Michael Lichtenstein, Peter Hornsby, Sara Espinoza and Dean Kellogg.

Contributors All authors: participated in study design. KRR and WLH: enrolled participants and completed study procedures. CNR and LSC: completed data analysis. All authors participated in data interpretation. KRR: wrote the original manuscript draft and all other authors edited the manuscript.

Funding KRR is supported by the National Institutes of Health/National Institute on Aging San Antonio Claude D Pepper Older Americans Independence Center (1P30AG044271-01A1) Career Development (KL2) Program.

Competing interests None declared.

Patient consent Obtained.

Ethics approval UT Health San Antonio.

Provenance and peer review Not commissioned; internally peer reviewed.

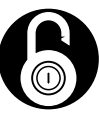

\section{OPEN ACCESS}

Open Access This is an Open Access article distributed in accordance with the Creative Commons Attribution Non Commercial (CC BY-NC 4.0) license, which permits others to distribute, remix, adapt, build upon this work non-commercially, and license their derivative works on different terms, provided the original work is properly cited and the use is non- commercial. See: http://creativecommons.org/licenses/ by-nc/4.0/

(C) Article author(s) (or their employer(s) unless otherwise stated in the text of the article) 2018. All rights reserved. No commercial use is permitted unless otherwise expressly granted.

$$
\text { D) Check for updates }
$$

To cite Reveles KR, Ryan CN, Chan L, et al. Gut 2018;67:1369-1370.

Received 18 September 2017

Revised 25 September 2017

Accepted 27 September 2017

Published Online First 9 October 2017

Gut 2018;67:1369-1370. doi:10.1136/

gutjnl-2017-315306

\section{REFERENCES}

1 Imhann F, Bonder MJ, Vich Vila A, et al. Proton pump inhibitors affect the gut microbiome. Gut 2016:65:740-8.

2 Jackson MA, Goodrich JK, Maxan ME, et al. Proton pump inhibitors alter the composition of the gut microbiota. Gut 2016;65:749-56.

3 Reimer C, Bytzer P. Clinical trial: long-term use of proton pump inhibitors in primary care patients - a cross sectional analysis of 901 patients. Aliment Pharmacol Ther 2009;30:725-32.

4 O'May GA, Reynolds N, Smith AR, et al. Effect of pH and antibiotics on microbial overgrowth in the stomachs and duodena of patients undergoing percutaneous endoscopic gastrostomy feeding. J Clin Microbiol 2005;43:3059-65.

5 Sanaka M, Yamamoto T, Kuyama Y. Effects of proton pump inhibitors on gastric emptying: a systematic review. Dig Dis Sci 2010;55:2431-40.

6 Hopkins MJ, Macfarlane GT. Changes in predominant bacterial populations in human faeces with age and with Clostridium difficile infection. J Med Microbiol 2002;51:448-54.

7 Valdés-Varela L, Hernández-Barranco AM, Ruas-Madiedo $P$, et al. Effect of bifidobacterium upon clostridium difficile growth and toxicity when co-cultured in different prebiotic substrates. Front Microbiol 2016;7:738.

8 Gu S, Chen Y, Zhang X, et al. Identification of key taxa that favor intestinal colonization of Clostridium difficile in an adult Chinese population. Microbes Infect 2016;18:30-8.

9 Kwok CS, Arthur AK, Anibueze Cl, et al. Risk of Clostridium difficile infection with acid suppressing drugs and antibiotics: meta-analysis. Am J Gastroenterol 2012;107:1011-9. 